\title{
Ultrabithorax confers spatial identity in a context-specific manner in the Drosophila postembryonic ventral nervous system
}

Elizabeth C Marin ${ }^{1,2,3^{*}}$, Katie E Dry ${ }^{1}$, Danielle R Alaimo ${ }^{2}$, Kirstin T Rudd ${ }^{2}$, Anthony R Cillo ${ }^{3}$, Michael E Clenshaw ${ }^{1}$, Nicolas Negre ${ }^{4}$, Kevin P White ${ }^{4}$ and James W Truman ${ }^{5}$

\begin{abstract}
Background: In holometabolous insects such as Drosophila melanogaster, neuroblasts produce an initial population of diverse neurons during embryogenesis and a much larger set of adult-specific neurons during larval life. In the ventral CNS, many of these secondary neuronal lineages differ significantly from one body segment to another, suggesting a role for anteroposterior patterning genes.

Results: Here we systematically characterize the expression pattern and function of the Hox gene Ultrabithorax $(U b x)$ in all 25 postembryonic lineages. We find that Ubx is expressed in a segment-, lineage-, and hemilineage-specific manner in the thoracic and anterior abdominal segments. When Ubx is removed from neuroblasts via mitotic recombination, neurons in these segments exhibit the morphologies and survival patterns of their anterior thoracic counterparts. Conversely, when Ubx is ectopically expressed in anterior thoracic segments, neurons exhibit complementary posterior transformation phenotypes.

Conclusion: Our findings demonstrate that Ubx plays a critical role in conferring segment-appropriate morphology and survival on individual neurons in the adult-specific ventral CNS. Moreover, while always conferring spatial identity in some sense, Ubx has been co-opted during evolution for distinct and even opposite functions in different neuronal hemilineages.
\end{abstract}

Keywords: Hox, Programmed cell death, CNS, Neuroblast lineages

\section{Background}

The insect ventral CNS, like the body as a whole, is built on a plan of repeating segmental units that then undergo regional specialization. The neurons of a segmental unit arise from a stereotyped two-dimensional array of 30 uniquely identifiable neural stem cells (neuroblasts, NB) per hemisegment [1-3]. These NBs undergo repeated asymmetric divisions, thereby producing a series of ganglion mother cells, GMCs [4], each of which divides to produce a pair of postmitotic daughters $[5,6]$. These daughters then acquire distinct fates via Notch signaling $[7,8]$. In insects with complete metamorphosis, like Drosophila melanogaster, the NBs typically have an initial

\footnotetext{
* Correspondence: em031@bucknell.edu

'Biology Department, Bucknell University, Lewisburg, PA, USA

${ }^{2}$ Neuroscience Program, Bucknell University, Lewisburg, PA, USA

Full list of author information is available at the end of the article
}

burst of proliferation to generate the neurons of the larval CNS and then later a subset feature an extended proliferative period during larval life, producing most of the neurons of the adult CNS $[9,10]$. During the postembryonic neurogenic phase, Notch signaling between sibling cells produces two morphologically distinguishable cell types that accumulate to form two distinct hemilineages, one of which may be eliminated by programmed cell death [10].

In the embryo, the NB arrays are almost identical between thoracic and abdominal neuromeres [11], although there are some regional differences in the neurons produced by thoracic versus abdominal homologs [12-14]. During the postembryonic neurogenic phase, however, there are dramatic differences between the numbers of thoracic versus abdominal NBs [15]. Within the thorax

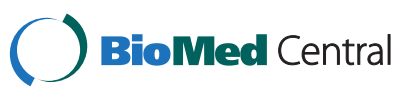


particular lineages exhibit segment-specific differences in their cellular composition [10].

Given their roles in anteroposterior patterning of the embryonic CNS (reviewed in [16]), the Hox genes are excellent candidates for conferring segmental identity in the postembryonic nervous system. For example, in late stage embryos, Abdominal-A (Abd-A) represses proliferation of many NBs in the abdomen [17], and a burst of $a b d-A$ expression causes the apoptosis of persistent abdominal lineages during the third instar $[17,18]$. Also, Ultrabithorax (Ubx) represses the formation of leg neuropils in the first abdominal segment (A1) [19], and in $U b x^{-}$animals, thoracic-specific NBs are retained in the A1 neuromere during the postembryonic neurogenic period [20].

The development of methods to label and manipulate NB lineages [21] has allowed the detailed characterization of the postembryonic lineages that generate the adultspecific neurons $[9,10]$. Using these methods we find that $U b x$ is expressed in a segment-, lineage-, and siblingspecific manner that correlates with morphological differences observed in different segments for particular lineages. Moreover, removal of $U b x$ from a lineage via the MARCM (mosaic analysis with a repressible cell marker) method results in anterior transformation of its morphology and survival pattern, whereas ectopic expression of $U b x$ results in posterior transformation. Interestingly, $U b x$ can promote survival, death, and/or segment-specific changes in neurite morphology, depending on the hemilineage. Taken together, these data demonstrate that $U b x$ has been co-opted during evolution to regulate the segmental identity of secondary neurons in a contextdependent manner during development.

\section{Results}

Overview of Ubx expression in the larval nervous system As initially described by White and Wilcox [22], the major domain of Ubx expression in the embryonic CNS is parasegment 6 (Figure 1A), with weaker expression in parasegment 5 (posterior $\mathrm{T} 2$ and anterior $\mathrm{T} 3$ ) and an isolated cluster of neurons in the midline of parasegment 4. Posterior to A1, Ubx expression is weak and spotty but still occurs in some neurons through A7. Within parasegment 6 , the great majority of the neurons show strong Ubx expression (Figure 1A').

By the end of the last (third) larval stage, the larval neurons have been joined by clusters of secondary neurons. The former are in a compact layer next to the neuropil, whereas the latter are in superficial clusters that extend from the larval neuron layer to the surface of the CNS. The larval neurons show the same pattern of Ubx expression as seen at hatching (Figure 1B, C). Ubx expression in the postembryonic lineages is also mostly confined to parasegments 5 and 6, with that expression in the latter being stronger. However, unlike in the larval neurons, Ubx expression in the clusters of postembryonic-born neurons was quite heterogeneous, even in parasegment 6. The NBs and GMCs did not
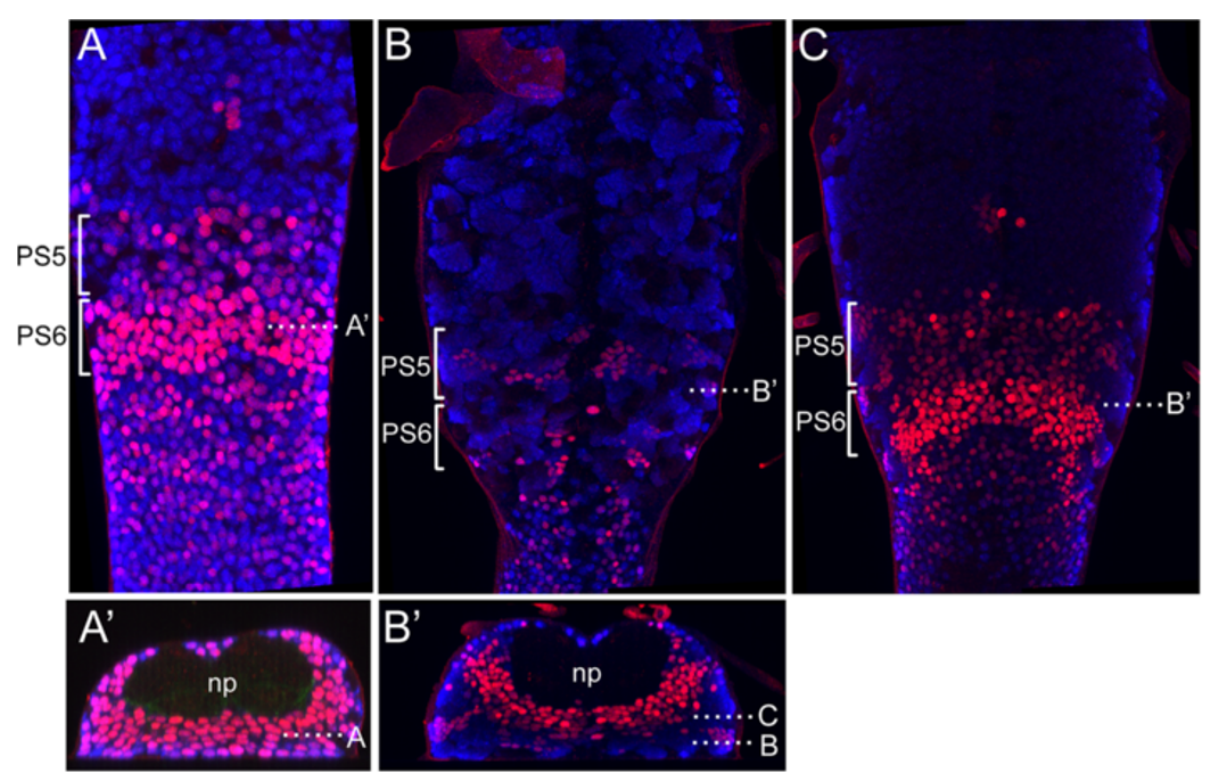

Figure 1 Expression of Ubx in the ventral CNS of first instar and late third instar larvae. (A) Dorsal projection showing Ubx expression (red) in parasegments (PS) 5 and 6. (A') Transverse projection at the indicated level in PS6. (B,C) Optical sections at the level of the adult-specific lineages $(\mathbf{B})$ and of the larval neurons $(\mathbf{C})$. ( $\left.\mathbf{B}^{\prime}\right)$ Transverse projection showing the level of the optical sections and the uniform expression in the larval neuron layer around the neuropil (np) and the variable staining of the adult-specific lineages. Blue: elav; np: neuropil; PS: parasegment; Ubx: Ultrabithorax. 
express Ubx, but Ubx expression within the associated cluster of postembryonic neurons varied from cluster to cluster (Figure $1 \mathrm{~B}, \mathrm{~B}^{\prime}$ ), suggesting a lineage-based regulation. The T2 lineages that exhibit any Ubx expression are $0,3,11,12$, and 19, all of which are in the engrailed domain (JWT \& D.W. Williams, unpublished work) and, thus, in the anterior portion of parasegment 5. These lineages express much higher levels of Ubx in T3 but fail to express it in A1 (parasegment 7). Ubx expression in the postembryonic lineages is summarized in Figure 2, and examples of expression patterns for the positive lineages are given in the following figures.

Lineages that were Ubx positive typically had all Ubx+ cells or roughly equal numbers of Ubx+ and Ubx- neurons. For the latter cases, our Ubx manipulations described below argue that one sibling from the GMC division becomes $\mathrm{Ubx}+$ and the other Ubx-, thereby resulting in roughly equal numbers of the two expression types. There were a few lineages in which Ubx expression appeared not to be divided along hemilineage lines.
Lineage 12 in segment T3 and lineage 1 in A1 both had a few Ubx+ cells apically, near the NB and GMCs. However, as shown below, in both lineages Ubx expression is responsible for the death of the neurons of one hemilineage, and the cells that we observed were the newly-born cells that had not yet initiated programmed cell death. Expression patterns that were clearly not hemilineage related were seen for the largely negative lineages 8,15 , and 23. Each had one to a few weakly Ubx+ neurons in T3, but our Ubx manipulations did not reveal a role for this expression.

\section{Ubx regulates segment-specific neuronal programmed cell death of particular hemilineages \\ Lineage 1}

Lineage 1 provides a striking example of segmentspecific survival in the secondary lineages. The neurons in the 1A hemilineage form the contralateral (1c) axon bundle that projects across the anterior ventral $(\mathrm{aV})$ commissure to the contralateral leg neuropil, and those

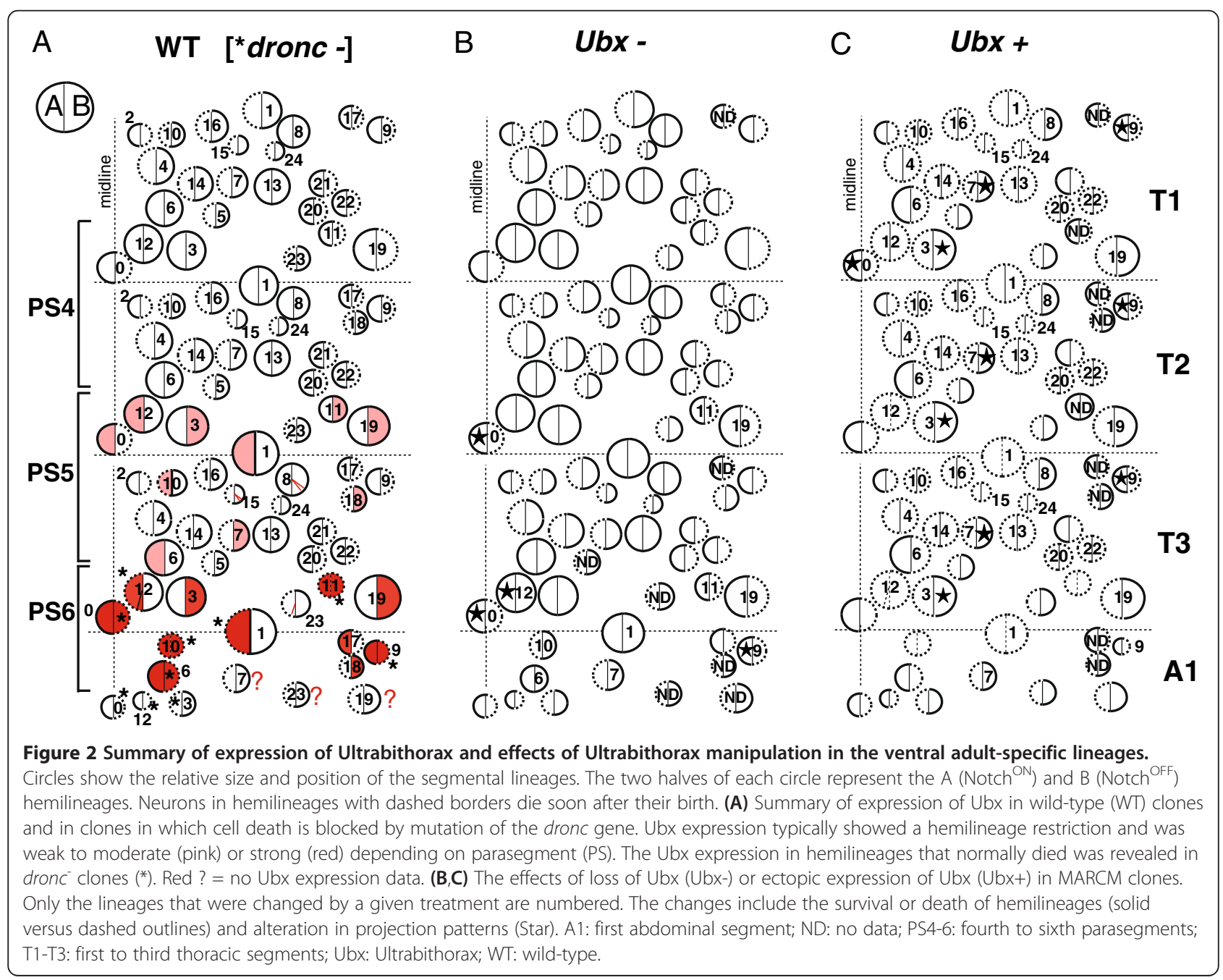


in the $1 \mathrm{~B}$ hemilineage form the ipsilateral (1i) bundle that projects to the next anterior leg neuropil [10]. Both hemilineages are present in segments T2 $(n=13 / 13,1 \mathrm{c}$ axon bundle diameter $=2.97 \pm 0.60 \mu \mathrm{m}$, Figure $3 \mathrm{~A}$ ) and T3 $(\mathrm{n}=12 / 12,3.06 \pm 0.37 \mu \mathrm{m}$, Figure 3B). However, in $\mathrm{T} 1$, the $1 \mathrm{~B}$ hemilineage that would have projected to $\mathrm{S} 3$ is absent [9] ( $n=7 / 9$, not shown) or truncated $(n=2 / 9$, not shown), while in A1, the contralaterally projecting 1A hemilineage is missing [9] $(n=4 / 9$, Figure $3 C)$ or exhibits only a few aborted axons ( $n=5 / 9$, not shown), resulting in a greatly reduced axon bundle with a diameter of only $0.83 \pm 0.91 \mu \mathrm{m}$. The absent or reduced hemilineages correlate with the absence of leg neuropils in S3 and A1.

We examined the Ubx expression pattern in wild-type (WT) and dronc clones. In WT clones in T1 $(n=3 / 3$, data not shown) and T2 $\left(n=7 / 7\right.$, Figure $\left.3 A^{\prime}\right)$, all lineage 1 cells were Ubx-, while approximately half of the cells in T3 clones were weakly positive for $\operatorname{Ubx}(n=3 / 3$, Figure $\left.3 \mathrm{~B}^{\prime}\right)$. In $\mathrm{A} 1$, all or most cells were Ubx-, with a few cells near the $\mathrm{NB}$ occasionally observed to be strongly positive $\left(n=3 / 5\right.$, Figure $\left.3 C^{\prime}\right)$. For dronc' clones, in which programmed cell death was blocked, the A1 cluster was enlarged and showed a robust 1c bundle consistent with the survival of the 1 A sibling $(n=11 / 12$, $2.91 \pm 0.56 \mu \mathrm{m}$, Figure $3 \mathrm{~F}$ ). Approximately half of the cells in the enlarged cluster were strongly positive for Ubx $\left(n=9 / 9\right.$, Figure $\left.3 F^{\prime}\right)$, suggesting that the 1 A sibling in A1 expresses a high level of Ubx prior to dying.
Loss and gain of function experiments confirmed that $U b x$ regulates the survival of lineage $1 \mathrm{~A}$ neurons. $U b x^{-}$ clones in A1 exhibited a robust 1c bundle as well as the expected $1 \mathrm{i}$ bundle $(\mathrm{n}=23 / 24,3.53 \pm 0.96 \mu \mathrm{m}$, Figure $3 \mathrm{I})$. Interestingly, the ectopic 1c bundle hooked upwards towards T3, rather than taking the expected trajectory towards the posterior part of the segment. A similar phenotype was also seen in dronc-clones for lineage 1 in segment A1. This altered pathway may be due to a lack of leg neuropil target cues in abdominal segments. The misexpression of $U b x$ in $U A S-U b x$ clones apparently led to the death of both hemilineages of lineage 1 neurons, regardless of segment. Only a few thoracic lineage 1 clones were observed, and those had few cells and very thin, faint projections, most likely indicating that the neurons were dying $(n=11 / 12$, axon bundle diameter $=1.80 \pm 0.27 \mu \mathrm{m}$, Figure 3J, K). Thus, a high level of Ubx expression can result in the death of the neurons of both hemilineages, although only hemilineage $1 \mathrm{~A}$ neurons normally express it. Also, although the hemilineage 1A neurons in T3 normally express a moderate level of Ubx, they die in response to the high levels in the MARCM clones. Therefore, the ability of Ubx to cause the death of these neurons appears to be concentration dependent.

\section{Lineage 6}

NB 6 produces two hemilineages: 6A, whose axon bundle $6 \mathrm{~cd}$ projects to the posterior dorsal (pD) commissure, and $6 \mathrm{~B}$, whose axon bundle $6 \mathrm{ci}$ projects along the
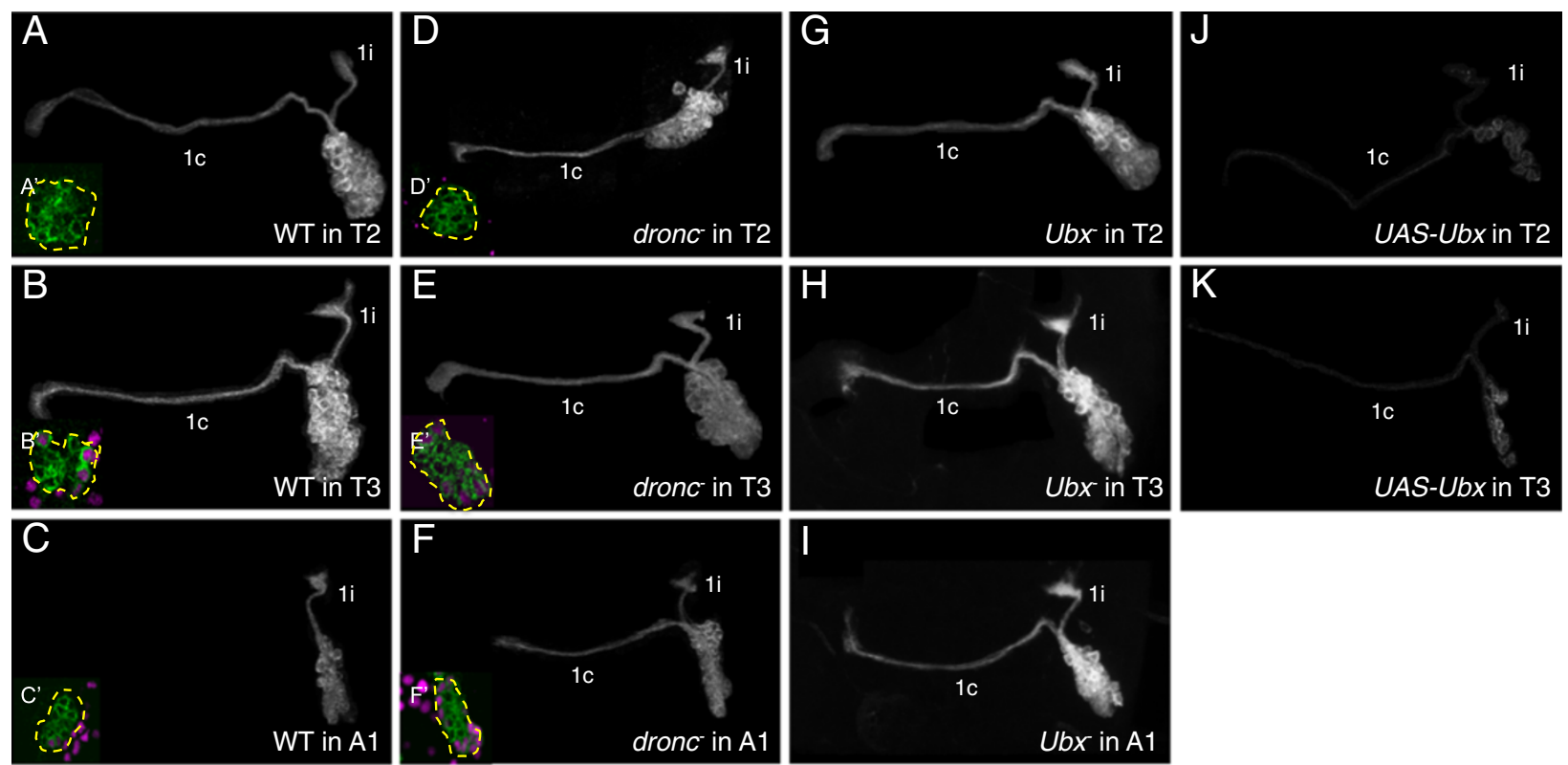

Figure 3 Dorsal view of neuroblast clones showing Ultrabithorax expression and genetic manipulation in lineage 1. Insets: Ubx expression (magenta) in a mid-clone optical section. (A-C) Wild-type clones. (C) Bundle 1c is absent in A1. (D-F) dronc clones. (F) Bundle 1C is present in A1. (G-I) Ubx clones. (I) Bundle 1C is present in A1. (J-K) UAS-Ubx clones. Bundles $1 \mathrm{i}$ and $1 \mathrm{C}$ are very thin and lack elaboration. White or green, anti-CD8. Ubx: Ultrabithorax. 
posterior intermediate $(\mathrm{pI})$ commissure before turning anteriorly [10] (T2: $n=13 / 13,6 \mathrm{ci}$ axon bundle diameter $=4.86 \pm 1.16 \mu \mathrm{m}$, Figure 4A; T3: $n=6 / 6,4.63 \pm 1.11$ $\mu \mathrm{m}$, Figure $4 \mathrm{~B})$. In segment $\mathrm{A} 1$, the $6 \mathrm{ci}$ bundle is significantly reduced and/or truncated [9] $(n=5 / 6$, $0.63 \pm 0.99 \mu \mathrm{m}$, Figure $4 \mathrm{C}$ ), suggesting decreased survival of the $6 \mathrm{~B}$ sibling. This was confirmed by dronc lineage 6 clones in A1 that featured robust 6ci bundles projecting from an enlarged cell body cluster $(\mathrm{n}=9 / 9,2.96 \pm 0.68 \mu \mathrm{m}$, Figure 4F).

WT lineage 6 clones lacked Ubx expression in T1 $(\mathrm{n}=12 / 12$, not shown) and T2 $(\mathrm{n}=14 / 14$, Figure 4A', A"), were weakly Ubx+ in T3 ( $n=12 / 22$, Figure 4B', B"), and were strongly $\mathrm{Ubx}+$ in $\mathrm{A} 1$ except for the youngest cells $(n=15 / 15$, Figure 4C,C"). dronc clones in A1 also featured strong Ubx expression in all but the youngest cells $(n=7 / 7$, Figure 4F,'F"), implying that most or all of the $6 \mathrm{~B}$ siblings that typically die in $\mathrm{A} 1$ also express high levels of Ubx.
In comparison with WT lineage 6 clones in A1, $U b x$ clones were larger and exhibited a robust $6 \mathrm{ci}$ bundle $(\mathrm{n}=7 / 7,4.26 \pm 0.74 \mu \mathrm{m}$, Figure $4 \mathrm{I})$, indicating the survival of the $6 \mathrm{~B}$ hemilineage. Conversely, with ectopic expression of $U b x$ in lineage 6 , the $6 \mathrm{ci}$ bundle was much reduced or absent in all segments (T2: $n=16 / 17$, $0.41 \pm 0.77 \mu \mathrm{m}$, Figure 4J; T3: $\mathrm{n}=22 / 22,0.49 \pm 0.97 \mu \mathrm{m}$, Figure 4K; A1: $n=16 / 16,0 \pm 0 \mu \mathrm{m}$, Figure 4L), although the $6 \mathrm{~cd}$ bundle was present throughout. These results show that a high level of Ubx expression is both necessary and sufficient for death of the $6 \mathrm{~B}$ but not the $6 \mathrm{~A}$ hemilineage.

\section{Lineage 19}

In the thorax, the neurons of the 19A hemilineage projects diffusely into the ipsilateral leg neuropil via bundle $19 \mathrm{i}$, whereas those of the 19B hemilineage form bundle 19c, which projects contralaterally in the pI commissure [10]. Both hemilineages are found in T2 $(n=5 / 5,19 \mathrm{c}$ axon
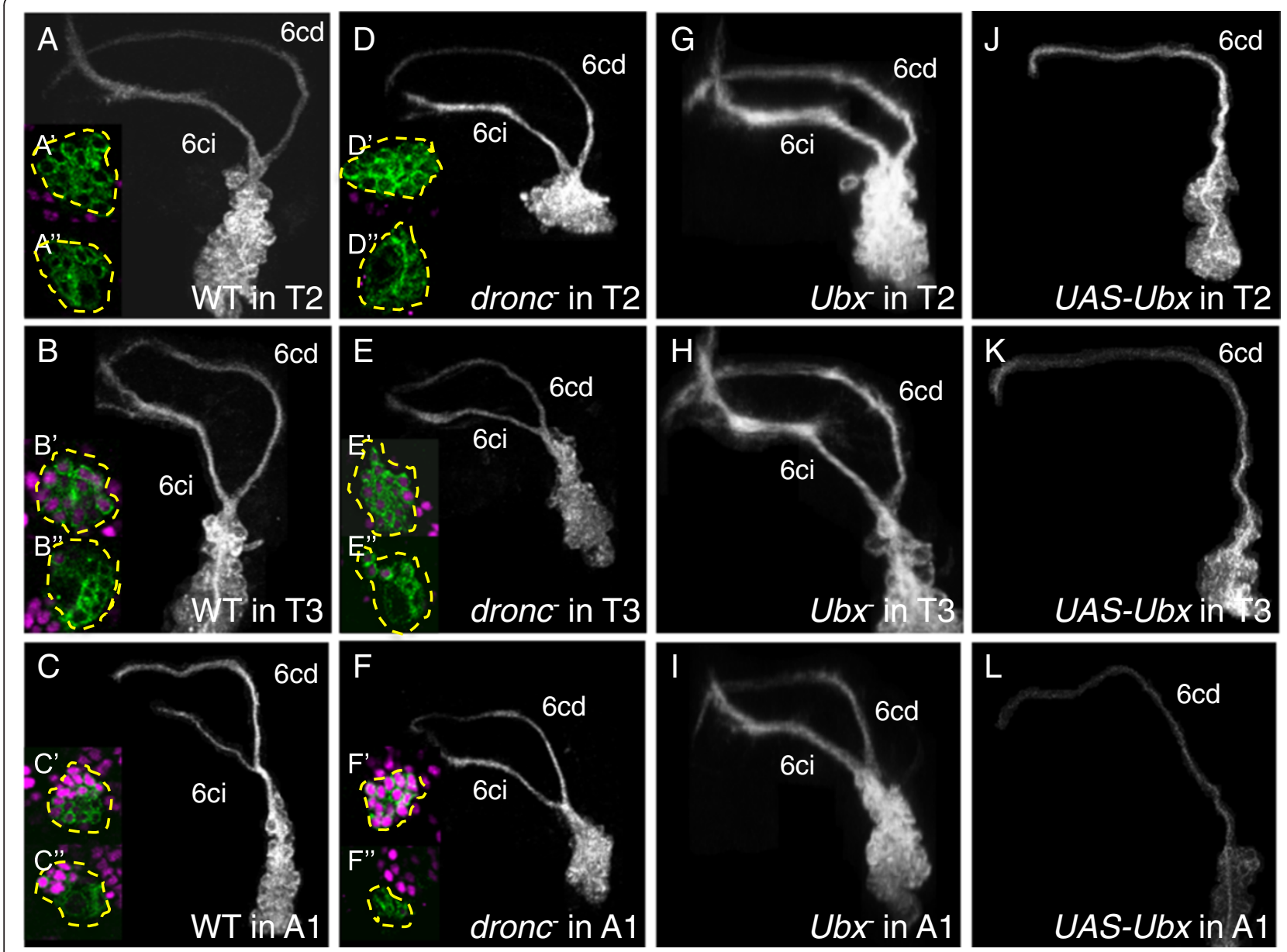

Figure 4 Dorsal view of neuroblast clones showing Ultrabithorax expression and genetic manipulation in lineage 6. Insets: Ubx expression (magenta) at mid-clone (upper) or next to neuroblast (lower). (A-C) Wild-type clones. (C) Bundle 6ci is thin and truncated in A1. (D-F) dronc clones. (F) Bundle $6 \mathrm{ci}$ is robust in A1. (G-I) Ubx clones. (I) Bundle $6 \mathrm{ci}$ is robust in A1. (J-L) UAS-Ubx clones. Bundle $6 \mathrm{ci}$ is missing in all segments. White or green, anti-CD8. Ubx: Ultrabithorax. 
bundle diameter $4.52 \pm 1.42 \mu \mathrm{m}$, Figure $5 \mathrm{~B})$ and T3 $(\mathrm{n}=8$ / $8,4.15 \pm 0.38 \mu \mathrm{m}$, Figure $5 \mathrm{C}$ ), but in $\mathrm{T} 1$ there are only a few contralaterally projecting $19 \mathrm{~B}$ cells, resulting in a greatly reduced $19 \mathrm{c}$ bundle $(\mathrm{n}=3 / 3,0.61 \pm 1.06 \mu \mathrm{m}$, Figure 5A) [9]. In $\mathrm{A} 1$, by contrast, the $19 \mathrm{~B}$ cells are present and form a robust 19c bundle, but the 19A cells are absent $(n=1 / 1$, Figure $5 D)$. Ubx expression was absent from WT T1 clones $\left(n=12 / 12\right.$, Figure $\left.5 A^{\prime}\right)$. About half of the cells in T2 clones showed weak Ubx expression $\left(n=10 / 12\right.$, Figure $\left.5 B^{\prime}\right)$, and about half of the cells in T3 clones were strongly $\mathrm{Ubx}+\left(\mathrm{n}=15 / 15\right.$, Figure $\left.5 C^{\prime}\right)$. Cells contributing to $19 \mathrm{c}$ in the A1 lineage 19 clones were Ubx$\left(\mathrm{n}=1 / 1\right.$, Figure $\left.5 \mathrm{D}^{\prime}\right)$.

In dronc ${ }^{-} \mathrm{T} 1$ clones, both the $19 \mathrm{~A}$ and $19 \mathrm{~B}$ hemilineages were present, judging from the increased thickness of the $19 \mathrm{c}$ bundle $(\mathrm{n}=10 / 10,4.23 \pm 0.75 \mu \mathrm{m}$, Figure 5E), but there still was no Ubx expression $\left(n=7 / 7\right.$, Figure $\left.5 E^{\prime}\right)$, indicating that the $19 B$ neurons are normally Ubx- in that segment. dronc clones in T2 $(\mathrm{n}=7 / 7,19 \mathrm{c}$ axon bundle diameter $4.36 \pm 0.24 \mu \mathrm{m}$, Figure 5F; $\mathrm{n}=3 / 4$, Figure $\left.5 \mathrm{~F}^{\prime}\right)$ and T3 $(\mathrm{n}=10 / 10$, $4.03 \pm 0.51 \mu \mathrm{m}$, Figure 5G; $n=7 / 7$, Figure 5G') exhibited morphologies and Ubx expression patterns that were identical to those of WT. In segment A1, dronc clones were enlarged and showed a 19i projection diagnostic of the survival of 19A neurons $(\mathrm{n}=1$, Figure $5 \mathrm{H})$. However, no A1 dronc clones counterstained for Ubx expression were recovered.
With the loss of $U b x$, lineage 19 clones in T2 $(\mathrm{n}=6 / 6$, axon bundle diameter $1.69 \pm 1.47 \mu \mathrm{m}$, Figure 5J) and T3 $(\mathrm{n}=8 / 8,1.39 \pm 1.49 \mu \mathrm{m}$, Figure $5 \mathrm{~K})$ had few or no axons in the $19 \mathrm{c}$ bundle, suggesting that most of the $19 \mathrm{~B}$ neurons had died, and that $U b x$ is required for the survival of the thoracic 19B neurons. Accordingly, overexpressing $U b x$ resulted in a robust $19 \mathrm{c}$ bundle in T1 $(\mathrm{n}=9 / 9$, $4.80 \pm 0.59 \mu \mathrm{m}$, Figure 5L) as well as T2 $(\mathrm{n}=19 / 19$, $4.90 \pm 0.77 \mu \mathrm{m}$, Figure $5 \mathrm{M})$ and T3 $(\mathrm{n}=7 / 7$, $5.49 \pm 0.56 \mu \mathrm{m}$, Figure $5 \mathrm{~N}$ ), but the $19 \mathrm{~A}$ neurons that produce the 19i bundle were missing from all three thoracic segments $(\mathrm{n}=30 / 30)$. Surprisingly, $U b x$ is both necessary and sufficient for the survival of the 19B siblings in the thorax, but can cause death of the 19A siblings. No $U b x^{-}$or $U A S-U b x$ clones were recovered in A1 (parasegment 7), where the fates of lineage 19 neurons may be out of the domain of Ubx action.

\section{Ubx confers segment-specific projections on particular hemilineages \\ Lineage 0}

In lineage 0 clones in T1, a single interneuron axon bundle from the 0A sibling [10] projects anterodorsally along the midline and terminates diffusely on the commissure $(\mathrm{n}=4 / 4$, Figure $6 \mathrm{~A})$. However, in $\mathrm{T} 2(\mathrm{n}=4 / 5$, Figure $6 \mathrm{~B})$, T3 $(n=3 / 3$, Figure $6 C)$, and A1 $(n=4 / 4$, Figure $6 \mathrm{D})$, the $0 \mathrm{~A}$ bundle extends further to the anterior intermediate commissure (aI) [9]. We see the same segment-specific

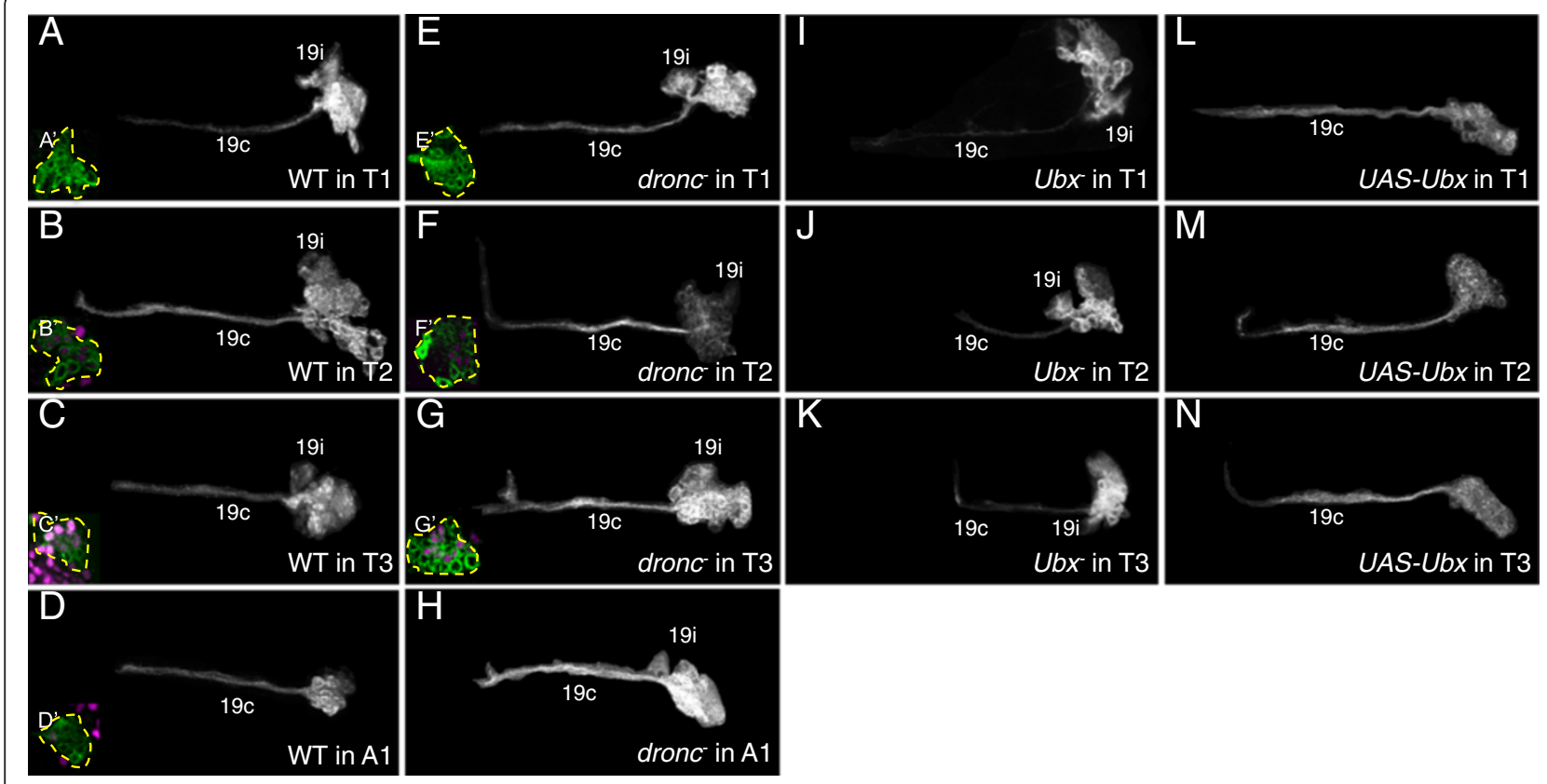

Figure 5 Dorsal view of neuroblast clones showing Ultrabithorax expression and genetic manipulation in lineage 19. Insets: Ubx expression (magenta) at mid-clone. (A-D) Wild-type clones. (A) Bundle 19c is thin and truncated in T1. (D) Bundle 19i is absent in A1. (E-H) dronc clones. (E) Bundle 19c is robust in T1. (H) Bundle 19i is present but lacks elaboration in A1. (I-K) Ubx clones. Bundle 19c is very thin in all segments. (L-N) UAS-Ubx clones. Bundle 19i is missing in all segments. White or green, anti-CD8. Ubx: Ultrabithorax. 

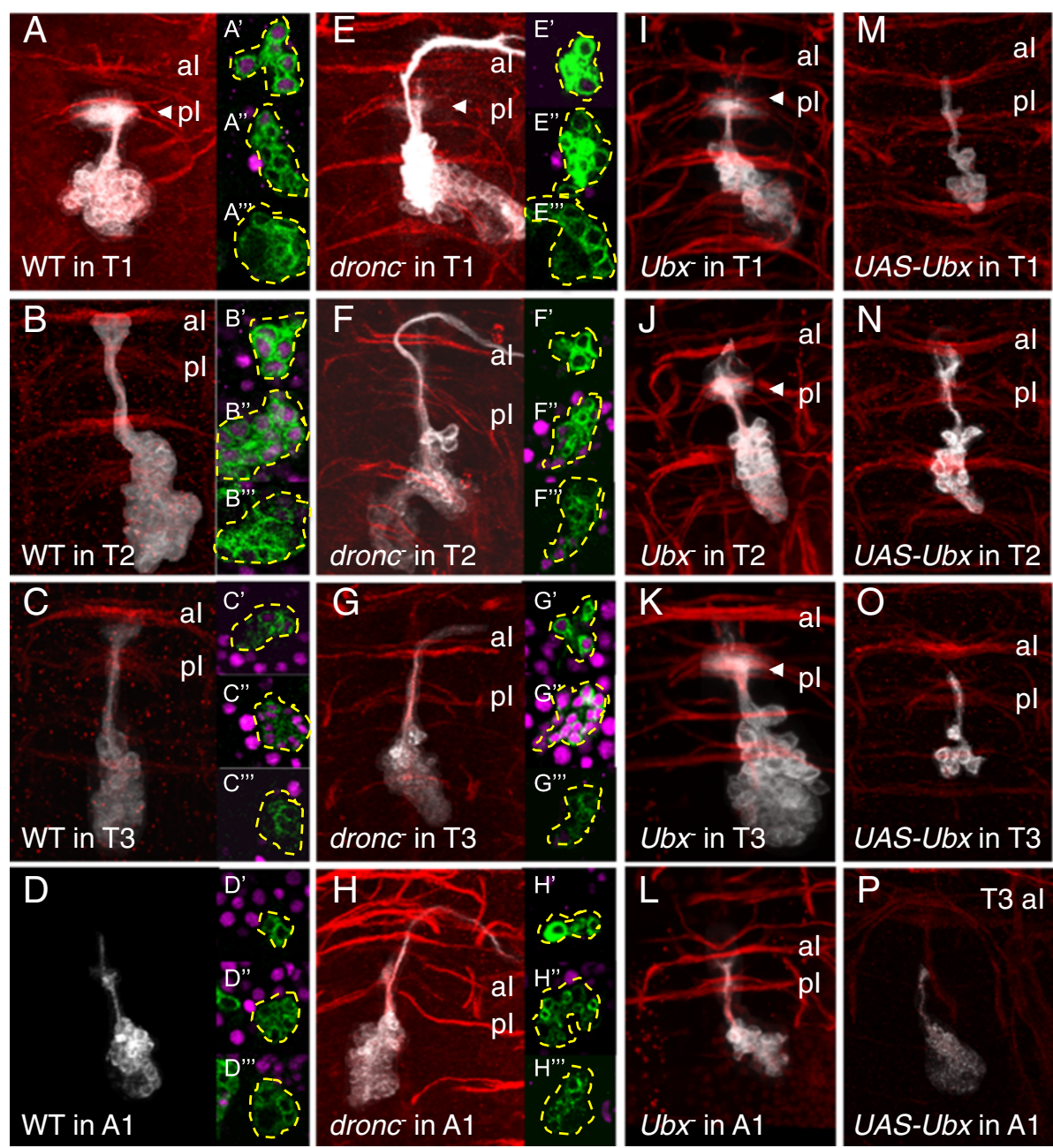

Figure 6 Dorsal view of neuroblast clones showing Ultrabithorax expression and genetic manipulation in lineage 0. Insets: Ubx expression (magenta) at basal (upper), middle (middle), or apical (lower) parts of clone. (A-D) Wild-type clones. (A) Bundle Oim terminates and elaborates in the pl in $\mathrm{T} 1$ (arrowhead). (E-H) dronc clones. A second axon bundle extending past the al and turning laterally appears in all segments. (E) Bundle Oim terminates and elaborates in the pl in T1 (arrowhead). (I-L) Ubx clones. Bundle Oim terminates and elaborates in the pl in T2 (J) and T3 (K). (M-P) UAS-Ubx clones. (M) Bundle Oim terminates in the al in T1. White or green = anti-CD8; red = anti-neurotactin. al: anterior intermediate commissure; pl: posterior intermediate commissure; Ubx: Ultrabithorax.

targeting of these interneurons in dronc clones (T1: $\mathrm{n}=6 / 6$, Figure 6E; T2: $\mathrm{n}=9 / 10$, Figure 6F; T3: $\mathrm{n}=2 / 5$, Figure 6G; $A 1: n=5 / 5$, Figure $6 \mathrm{H})$, but the local interneurons are now joined by the surviving $0 \mathrm{~B}$ projection neurons.

The distinct targets of the $0 \mathrm{~A}$ neurons are correlated with differences in their expression of Ubx. WT cell clusters in $\mathrm{T} 1$ ( $\mathrm{n}=10 / 11$, Figure $\left.6 \mathrm{~A}^{\prime}-\mathrm{A}^{\prime \prime}\right)$ were Ubx- except for the oldest (possibly embryonic born) cells, while those in T2 exhibited moderate levels of Ubx in older cells ( $n=4 / 7$, Figure 6B'-B'") and those in T3, high levels of Ubx in all but the oldest and youngest cells $(n=10 / 10$, Figure 6C'-C"'). WT clones in A1 (parasegment 7) were negative for Ubx expression ( $n=4 / 4$, Figure 6D'-D"'). Similar Ubx expression patterns were seen in dronc clones in all four segments (T1, n=3/4, Figure 6E'-E"'; $\mathrm{T} 2, \mathrm{n}=4 / 6$, Figure $6 \mathrm{~F}^{\prime}-\mathrm{F}^{\prime \prime} ; \mathrm{n}=5 / 5$, Figure $6 \mathrm{G}^{\prime}-\mathrm{G}^{\prime \prime} ; \mathrm{A} 1$, $\mathrm{n}=4 / 5$, Figure $\left.6 \mathrm{H}^{\prime}-\mathrm{H}^{\prime \prime}\right)$.

In $U b x^{-}$clones, the $0 \mathrm{~A}$ interneurons in $\mathrm{T} 2(\mathrm{n}=5 / 5$, Figure 6J) and T3 ( $n=7 / 7$, Figure $6 \mathrm{~K})$ adopted a T1-like morphology, projecting diffusely over the $\mathrm{pI}$ commissure. Conversely, with ectopic expression of Ubx, the OA interneurons in $\mathrm{T} 1$ adopted a posterior morphology, now projecting to the aI commissure $(n=13 / 15$, Figure $6 M)$. Taken together, these data demonstrate that $U b x$ acts to specify the segment-appropriate axon morphology of lineage 0 neurons in the thoracic neuromeres. Consistent with their lack of Ubx expression in WT or dronc clones, the axon morphology of A1 clones were unaffected by Ubx manipulation $(n=3 / 3$, Figure $6 L)$. 


\section{Lineage 9}

In the thorax, lineage 9 exhibits a robust ipsilateral projection (9i) that curls around the leg neuropil and a thin contralateral projection $(9 \mathrm{c})$ that crosses the midline in the aV commissure [9] $(\mathrm{n}=4 / 4$, Figure 7A). However, both of these projections are generated by the neurons of hemilineage 9A [10], while neurons from the 9B hemilineage typically die but survive in dronc ${ }^{-}$clones to generate a more dorsal contralateral projection (bundle 9ic) $(\mathrm{n}=9 / 11$, Figure 7D). In A1, the 9A hemilineage is smaller, with a $9 \mathrm{i}$ projection that is less pronounced and travels a short distance with bundle 9c $(n=4 / 5$, Figure $7 B)$. dronc $^{-}$clones in A1 are similar to WT except they have the dorsal 9ic bundle $(n=3 / 4$, Figure $7 E)$. In segment A2, the $9 \mathrm{i}$ bundle is no longer distinguishable from $9 \mathrm{c}$ in either WT $(n=4 / 5$, Figure $7 C)$ or dronc clones $(n=3 / 3$, Figure 7F).

WT lineage 9 clones in T3 did not express Ubx $(n=10 / 10$, Figure 7A'), but most cells of those in A1 were strongly $\mathrm{Ubx}+\left(\mathrm{n}=8 / 9\right.$, Figure $\left.7 \mathrm{~B}^{\prime}\right)$, while those in A2 were Ubx- $\left(n=8 / 8\right.$, Figure $\left.7 C^{\prime}\right)$. dronc clones in T3 were Ubx- $(n=3 / 3$, Figure 7D'), while those in A1 featured strong Ubx expression ( $n=4 / 4$, Figure $\left.7 E^{\prime}\right)$ and those in A2 were mixed Ubx + and Ubx- $(n=2 / 2$, Figure 7F').

$U b x^{-}$clones in T3 looked normal ( $n=9 / 13$, Figure $7 \mathrm{G}$ ), but those in A1 were larger and exhibited a much more robust and diffuse $9 \mathrm{i}$ process as compared with WT $(\mathrm{n}=4 / 5$, Figure $7 \mathrm{H})$. $U b x^{-}$clones in A2 either featured more robust $9 \mathrm{i}$ projections traveling along with 9c $(n=8 / 14)$ or an additional, more dorsal contralateral projection similar to those seen in $d r o n c^{-}$ clones $(\mathrm{n}=7 / 14$, Figure $7 \mathrm{I})$. For thoracic $U A S-U b x$ MARCM clones, the $9 \mathrm{i}$ bundle was either absent ( $\mathrm{n}=2 / 15$ for T3, not shown) or remained closely associated with the $9 \mathrm{c}$ bundle and lacked the characteristic medial "hook" ( $\mathrm{n}=11 / 15$ for T3, Figure 7J). These results suggest that for lineage 9, $U b x$ regulates both cell survival and axon guidance in A1 and A2.

\section{Lineage 12}

For lineage 12, the $12 \mathrm{~A}$ neurons form the $12 \mathrm{i}$ bundle to presumed flight neuropil, and the $12 \mathrm{~B}$ neurons form the $12 \mathrm{c}$ bundle that extends to the contralateral leg neuropil [10]. Both hemilineages are present in T1 $(n=6 / 6$, Figure $8 \mathrm{~A})$ and T2 $(\mathrm{n}=4 / 4$, Figure $8 \mathrm{~B})$, although in T1 the $12 \mathrm{i}$ bundle always exhibits a dorsal bifurcation, 12im [9], whereas in T2 it may or may not be branched depending on genetic background (data not shown). In T3, the $12 \mathrm{~A}$ hemilineage producing the $12 \mathrm{i}$ bundle is absent $(n=3 / 5)$ or greatly reduced $(n=2 / 5)$ [9] (Figure $8 C$ ), while in $\mathrm{A} 1$ the $12 \mathrm{~B}$ hemilineage producing the $12 \mathrm{c}$ bundle is absent ( $n=2 / 2$, Figure $8 D)$.

WT T1 clones were negative for Ubx $(n=12 / 12$, Figure 8A,'A"). T2 clones were approximately half negative and half weakly positive for Ubx ( $n=8 / 11$, Figure 8B', B"), while T3 clones were mostly negative except for a few strongly positive cells near the NB ( $n=19 / 21$, Figure $\left.8 \mathrm{C}^{\prime}, \mathrm{C}^{\prime \prime}\right)$. In dronc clones in T3, both the $12 \mathrm{~A}$ and $12 \mathrm{~B}$ hemilineages were present, producing robust $12 \mathrm{i}$ and $12 \mathrm{c}$ axon bundles ( $n=7 / 7$, Figure $8 \mathrm{G}$ ), and the clusters were approximately half Ubx- and half strongly Ubx+ ( $\mathrm{n}=4 / 4$, Figure 8G,'G"). Thus, the few apical Ubx+ cells

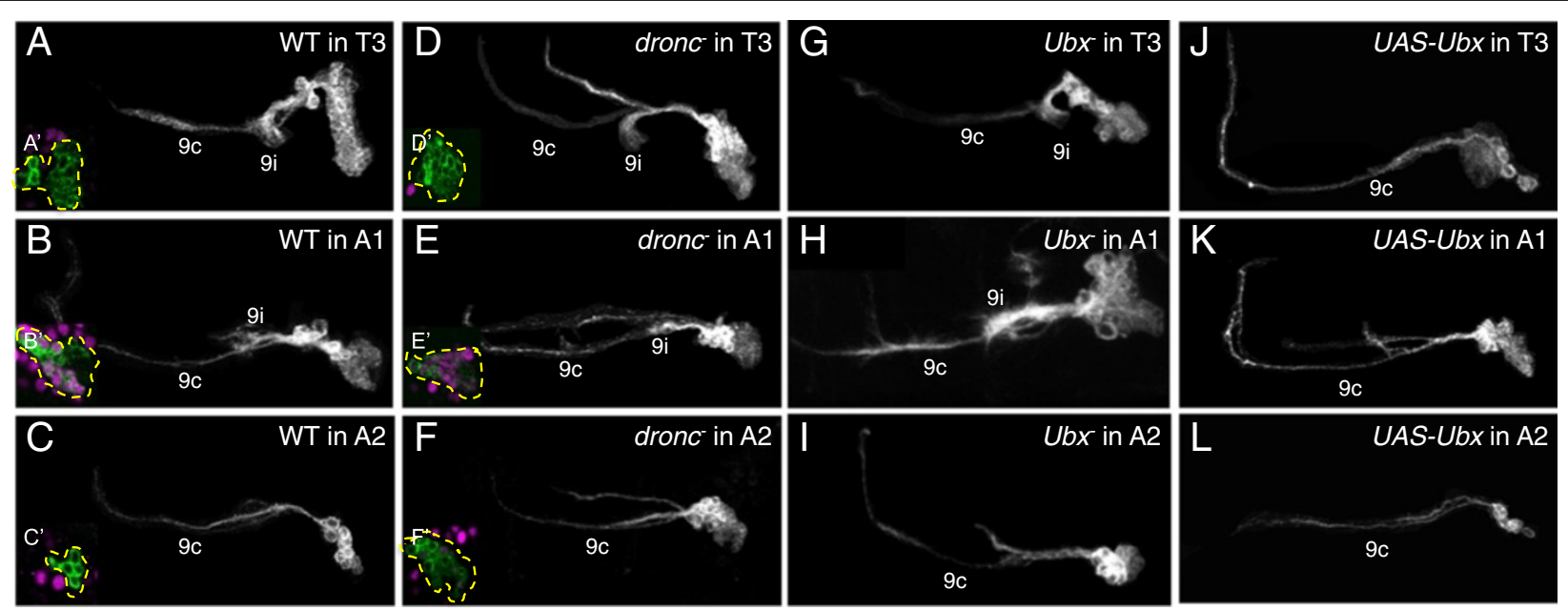

Figure 7 Dorsal view of neuroblast clones showing Ultrabithorax expression and genetic manipulation in lineage 9. Insets: Ubx expression (magenta) at mid-clone. (A-C) Wild-type clones. (A) Bundle $9 \mathrm{i}$ is robust and curls around leg neuropil in T3. (B) Bundle 9i is reduced and travels adjacent to $9 \mathrm{C}$ in $\mathrm{A}$ 1. (C) Bundle $9 \mathrm{i}$ is reduced and travels adjacent to bundle $9 \mathrm{c}$ in A2. (D-F) dronc clones. A second axon bundle appears in all segments. Bundle 9i follows same pattern as in wild-type. (G-I) Ubx clones. (H) Bundle 9i is robust and curls around leg neuropil in A1. (J-L) UAS-Ubx clones. Bundle $9 \mathrm{i}$ is missing or reduced and travels adjacent to bundle $9 \mathrm{c}$ in all segments. White or green, anti-CD8. Ubx: Ultrabithorax. 

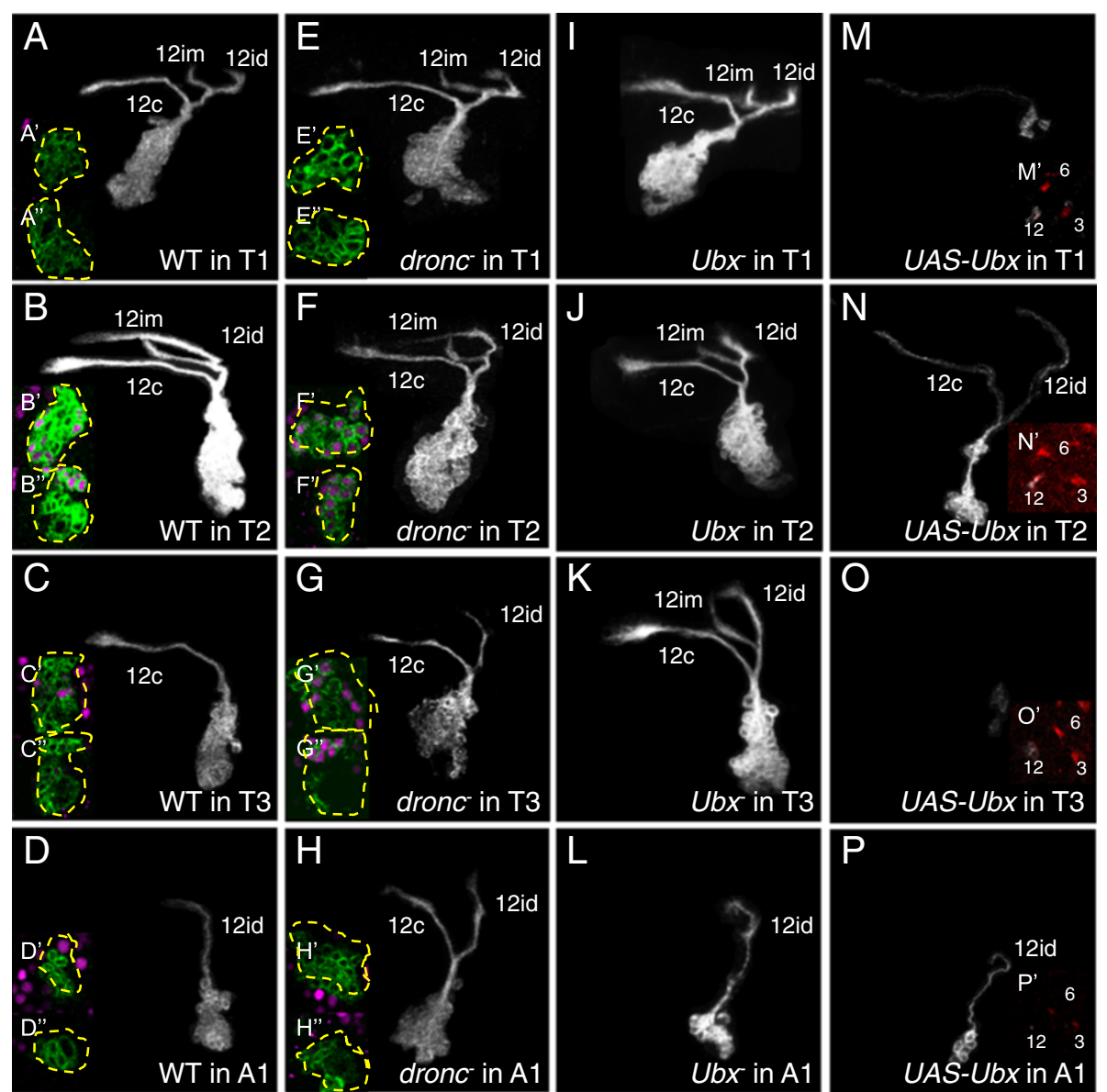

Figure 8 Dorsal view of neuroblast clones showing Ultrabithorax expression and genetic manipulation in lineage 12. Insets show either Ubx immunostaining (magenta) of sections at mid-clone $\left(\mathbf{A}^{\prime}-\mathbf{H}^{\prime}\right)$ or adjacent to the neuroblast $\left(\mathbf{A}^{\prime \prime}-\mathbf{H}^{\prime \prime}\right)$; or neurotactin immunostaining (red): single confocal slices shortly after the axon bundle enters the neurotactin scaffold ( $\left.\mathbf{M}^{\prime}-\mathbf{P}^{\prime}\right)$. (A-D) Wild-type clones. (C) Only bundle 12C is present in T3. (D) Only 12id is present in A1. (E-H) dronc clones. (G) Bundles 12c and 12id, but not 12im, are present in T3. (H) Bundles 12c and 12id, but not 12im, are present in A1. (I-L) Ubx clones. (K) Bundles 12im, id, and $\mathrm{c}$ are present in T3. (M-P) UAS-Ubx clones. Cell bodies are missing and axon bundles reduced or missing in all segments. ( $\left.\mathbf{M}^{\prime}-\mathbf{P}^{\prime}\right)$ Lineage 12 is still identifiable based on characteristic position in neurotactin scaffold. White or green, anti-CD8, Ubx: Ultrabithorax.

we observed in WT clones were likely newly born 12A neurons prior to their death. Interestingly, the $12 \mathrm{im}$ bifurcation was absent from all dronc clones in T3 as well as those in $A 1$ ( $n=7 / 7$, Figure $8 H)$.

$U b x^{-}$clones in $\mathrm{T} 3$ featured surviving $12 \mathrm{~A}$ neurons, which made a bifurcated 12im bundle $(n=9 / 10$, Figure $8 \mathrm{~K}$ ). This phenotype resembled that of WT lineage 12 clones in $\mathrm{T} 1$ rather than that of dronc clones in T3, indicating that $U b x$ confers segment-appropriate axon projection patterns of the $12 \mathrm{~A}$ neurons as well as regulating their death. In segment A1 (parasegment 7), by contrast, loss of $U b x$ had no apparent effect $(n=7 / 7$, Figure $8 \mathrm{~L}$ ), consistent with the absence of Ubx expression in both wild-type $\left(\mathrm{n}=16 / 16\right.$, Figure $\left.8 \mathrm{D}^{\prime}, \mathrm{D}^{\prime \prime}\right)$ and dronc $^{-}\left(\mathrm{n}=8 / 8\right.$, Figure $\left.8 \mathrm{H}^{\prime}, \mathrm{H}^{\prime \prime}\right)$ A1 clones.

Misexpression of $U b x$ caused the death of both 12A and $12 \mathrm{~B}$ siblings in all three thoracic segments, as evidenced by dramatically thinned and/or absent projections (T1: $\mathrm{n}=17 / 17$, Figure $8 \mathrm{M} ; \mathrm{T} 2: \mathrm{n}=4 / 4$, Figure $8 \mathrm{~N} ; \mathrm{T} 3: \mathrm{n}=8 / 8$, Figure $8 \mathrm{O}$ ) and no 12i bifurcation. The characteristic position of the lineage 12 bundle in the neurotactin scaffold relative to lineages 3 and 6 permitted unequivocal identification of this bundle even in the absence of CD8-GFPlabeled processes (Figures 8M, N,' O'). Where the clone should reside, we often saw a small cluster of cells with truncated or no projections. In such preparations the neurotactin-positive bundles (12i and 12c) were missing, confirming that these cells did not survive. These data strongly suggest that a high level of Ubx expression promotes the death of both lineage 12 siblings, while an intermediate level of Ubx permits survival but controls the segment-specific bifurcation of the 12i bundle.

In addition to these three examples, we also found a possible role for $U b x$ in determining the axon 
projections of lineages 3 and 7 (Figure 2). Overexpression of $U b x$ in lineage 3 resulted in survival of only the 3id sibling in the thoracic segments $(n=28 / 43)$, and the terminal elaborations normally found in $\mathrm{T} 1$ were missing $(n=43 / 43)$. Overexpression of $U b x$ in lineage 7 resulted in the axon bundle turning posteriorly instead of anteriorly $(n=16 / 51)$ or failing to turn $(n=32 / 51)$ after crossing the midline in all three thoracic segments (data not shown). However, given that there was no abnormal phenotype in $U b x^{-}$clones for either lineage, we cannot conclude definitively that $U b x$ normally regulates axon guidance in these lineages.

\section{Ubx promotes the programmed cell death of entire lineages \\ Lineage 10}

Lineage 10 is found only in the three thoracic segments and is represented there by only the $10 \mathrm{~B}$ hemilineage, which contributes the $10 \mathrm{c}$ bundle [10] $(n=1 / 1$, Figure 9A). These cells do not express $U b x(n=2 / 2$, Figure 9A'). dronc clones in the thoracic segments showed the additional $10 \mathrm{i}$ bundle, formed by the $10 \mathrm{~A}$ siblings that normally die [10] $(n=1 / 1$, Figure $9 B)$, and in
T3 such clones now had cells with moderate Ubx levels $(\mathrm{n}=1 / 1$, Figure 9B'). We recovered dronc clones in A1 $(\mathrm{n}=2 / 2$, Figure $9 \mathrm{C})$, and these were strongly Ubx+ $\left(\mathrm{n}=2 / 2\right.$, Figure 9C'). When we generated $U b x^{-}$clones, we also found lineage 10 clones in $\mathrm{A} 1$, although these only contained the $10 \mathrm{~B}$ hemilineage $(n=8 / 8$, Figure 9D). With the ectopic expression of $\mathrm{Ubx}$, we failed to find lineage 10 clones in any segment.

\section{Lineage 11}

Lineage 11 is normally present in $\mathrm{T} 1$ and $\mathrm{T} 2$, but not in T3 or in the abdomen [9]. Only the 11A hemilineage producing the $11 \mathrm{im}$ bundle is present in $\mathrm{T} 1(\mathrm{n}=3 / 3$, Figure 9E), while 11id is also present in T2 $(n=7 / 7$, Figure 9F), indicating the additional presence of the $11 \mathrm{~B}$ hemilineage. Suppression of cell death resulted in the appearance of both hemilineages in T3 $(n=2 / 3$, Figure 9I). Ubx expression in these neurons was weak in T2 $\left(n=5 / 6\right.$, Figure $\left.9 H^{\prime}\right)$ but very strong in T3 $(n=3 / 3$, Figure 9I'). The loss of $U b x$ also resulted in the appearance of lineage 11 clones in T3; however, only 11im was present, with 11 id greatly reduced or absent $(n=11 / 13$, Figure 9L). Interestingly, 11id was reduced or absent in

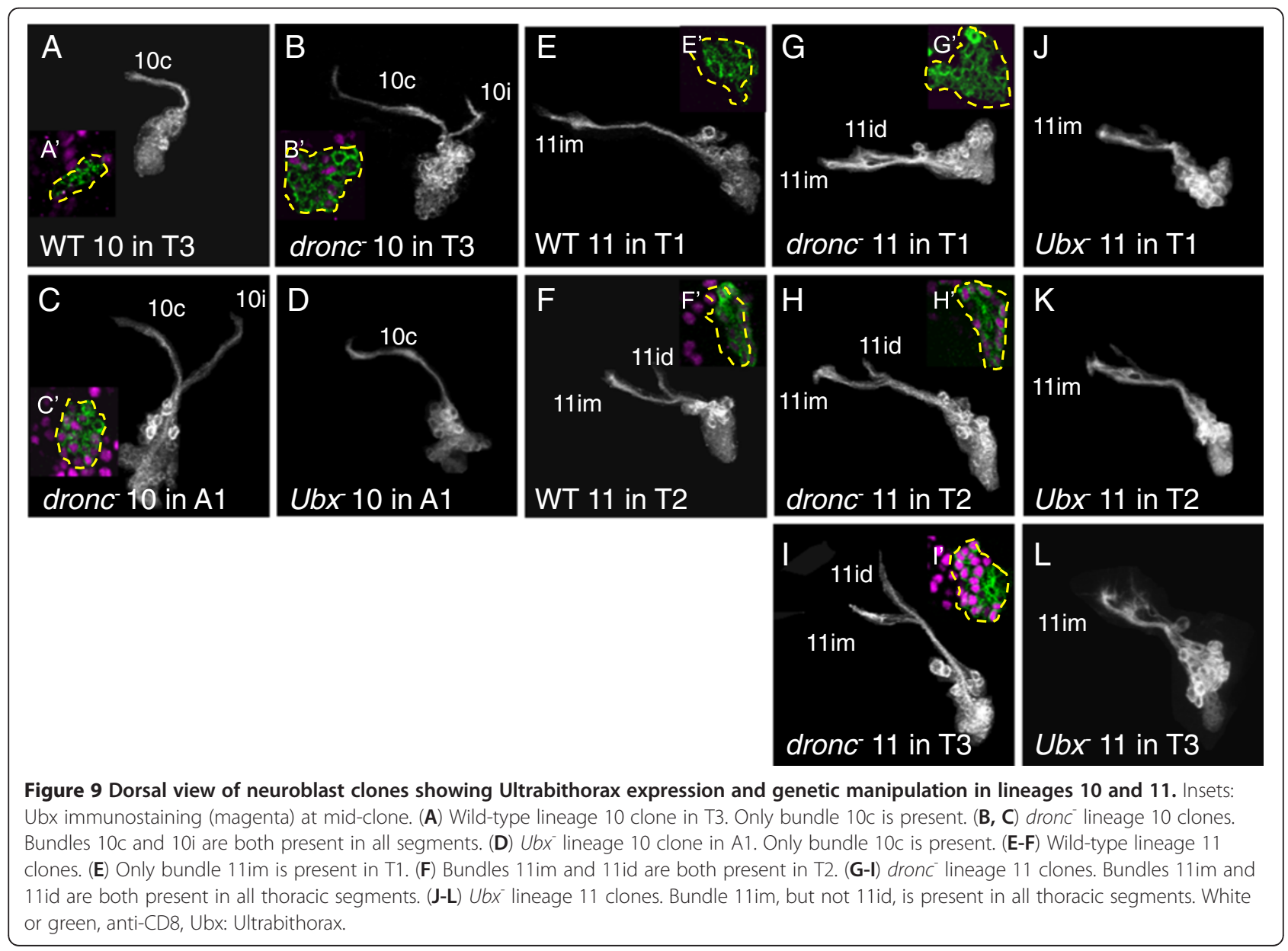


T2 $U b x^{-}$clones as well ( $n=12 / 15$, Figure 9K), indicating that a low level of Ubx is required for the survival of the $11 \mathrm{~B}$ neurons that produce the 11id bundle. We found no lineage 11 clones when we ectopically expressed $U b x$ in the $U A S-U b x$ experiments.

Based on these data, $U b x$ is responsible for the lack of lineage 11 neurons in T3 and of lineage 10 neurons in A1. One possibility is that $U b x$ causes the death of both siblings right after they are born. However, in WT individuals, we have not seen any indications of these lineages in the respective segments, but we typically look at the end of larval life, so the NB and all of its progeny may have died by that time. Alternatively, Ubx expression may cause the death of the NB itself. Previously it was reported that postembryonic NB survival in the ventral CNS is governed by the mutually exclusive expression and antagonistic functions of Antennapedia and $A b d-A$ but not $U b x$ [17]. The NBs that give rise to lineage 10 in A1 and to lineage 11 in T3 may be the exceptions to this rule.

\section{The ectopic expression of Ultrabithorax prevents survival of many Ubx negative lineages}

Of the 25 postembryonic lineages, 13 lineages are without Ubx expression in WT clones $(2,4,5,10,13$, $14,16,17,18,20,21,22$ and 24), and three express Ubx in just a few cells (8, 15 and 23) (Figure 2A). Because they are rarely labeled, we do not have Ubx misexpression data for lineages 5, 17 and 18. Within the remaining group of Ubx- lineages, lineages 2, 21 and 23 were unaffected by ectopic Ubx expression, and lineage 8 lost only the $8 \mathrm{~A}$ hemilineage (Figure 2C). The remaining Ubx- lineages $(4,10,13,14,15,16,20$, 22 and 24), along with lineages 1,11 and 12, all appeared to be killed by Ubx misexpression (Figure 2C). Of $375 U A S-U b x$ clones, we recovered only one robust example of a lineage from this group. In their place we often found reduced cell clusters that appeared to be degenerating clones with greatly reduced cell numbers and/or axon bundles (Figures 3J, $\mathrm{K}$ and $8 \mathrm{M}, \mathrm{N}, \mathrm{O}$; and not shown). By contrast, robust clones from these 12 lineages comprised 50\% $(n=170$ / 342) of WT clones, $47 \%(n=194 / 416)$ of dronc clones, and $54 \%(\mathrm{n}=317 / 592)$ of $U b x$ clones. Therefore, these Ubx- lineages retain the ability to respond to Ubx even though they do not express it.

\section{Discussion}

Ultrabithorax expression patterns in the embryonic and postembryonic ventral nervous system

Metamorphosis in Drosophila brings about a profound change in body form. Although the thoracic and abdominal segments have relatively similar morphologies in the larval body plan, they then diverge dramatically in the adult body plan. Within the adult thorax, there are additional segmental specializations to accommodate segment-constant features (legs) and segment-variable features (wings and halteres). These segmental specializations are sculpted by the Hox genes, with Ubx being the major gene effecting differences within the thorax. The difference in the complexity of the body of the larva versus the adult is paralleled by a difference in the complexity of Ubx expression during embryonic and postembryonic development of the nervous system.

At hatching, Ubx expression is observed in most neurons in parasegments 5 and 6, with expression in the latter being the stronger [23] (Figure 1). This expression pattern appears to be stable in the embryonic-born neurons throughout larval growth. We have found Ubx expression in the lineages of adultspecific neurons to be quite heterogeneous. With the exception of anterior expression in the median lineage, and extended posterior expression in lineage 9, Ubx expression is still confined to the lineages in parasegments 5 and 6 (posterior T2 through anterior A1). Each lineage, though, develops as an autonomous unit, and each adopts a characteristic pattern of Ubx expression, with the postembryonic neurons in a cluster being either all $\mathrm{Ubx}+$, all Ubx-, or mixed. In the case of mixed expression, Ubx expression is typically restricted to one hemilineage or the other, although it may be found in either the Notch ${ }^{\mathrm{ON}}$ or Notch ${ }^{\mathrm{OFF}}$ set of siblings (Figure 2).

For a given lineage or hemilineage, expression in parasegment 6 was higher than in parasegment 5 (Figures 3B, C, 4B,C, 5B,C, 6B,C, 8B,C and 9I,J). More extreme segmental differences in expression were seen for hemilineages $9 \mathrm{~A}$ and $17 \mathrm{~A}$, in which there was no expression in parasegment 5 but strong expression in parasegment 6 (Figure 2). There were no cases of 'flip-flopping", in which Ubx was expressed in one hemilineage in parasegment 5 but in the other hemilineage in parasegment 6 . In most cases, the different levels of expression we observed caused segment-specific differences in neuron survival and/or morphology (for example, hemilineages 1A, 6B, $12 \mathrm{~A}$ and $11 \mathrm{~B})$.

The expression of Ubx was highly correlated with whether or not a given hemilineage contributed to a segment-constant (leg neuropil) versus a segmentvariable (flight neuropil) portion of the CNS. Most of the hemilineages or lineages that contribute to the leg neuropils were Ubx- $(3 \mathrm{~A}, 4,8,9,13,14,15,16,20,21$, 22 and 24), the major exception being hemilineage 1B, in which Ubx causes the death of inappropriate leg interneurons in segment A1. Hemilineages that contribute to the dorsal flight neuropil, by contrast, were typically Ubx $+(0 \mathrm{~A}, 3 \mathrm{~B}, 6,7 \mathrm{~B}, 11 \mathrm{~B}, 12 \mathrm{~A}$ and 19B). 


\section{Multiple roles for Ubx in neuronal production and differentiation}

In the postembryonic nervous system, positional information conferred by Ubx has dramatically different consequences depending on hemilineage. As might be inferred from the many cases in which neurons that are present in anterior thoracic segments are absent from T3 or A1, Ubx expression promotes programmed cell death in numerous hemilineages including $1 \mathrm{~A}, 6 \mathrm{~B}, 9 \mathrm{~A}$, 12A and 19A. By contrast, for hemilineages 19B and $11 \mathrm{~B}$, neurons are missing from an anterior segment (T1), and in these cases $U b x$ is required for hemilineage survival (Figures 5 and 9). Lineage 19 strikingly shows this dichotomy of context dependence since its B $\left(\right.$ Notch $^{\mathrm{OFF}}$ ) sibling requires Ubx for survival, whereas its A $\left(\right.$ Notch $\left.^{\mathrm{ON}}\right)$ sibling is killed by Ubx expression. Besides being involved in the selective death or survival of hemilineages, Ubx also regulates the segment-specific survival of whole lineages, as in the case of lineage 11 in T3 and lineage 10 in segment A1 (Figure 9), although, as discussed earlier, we cannot be certain whether this is executed at the level of the postmitotic neurons or the NBs themselves. While the latter two lineages make use of Ubx expression to remove lineages from inappropriate segments, many of the leg-related lineages have shut off Ubx expression to insure the survival of their neurons in the normal Ubx domain of expression. Therefore, we see that the ectopic expression of Ubx in these lineages results in their death, independent of segmental location (Figures 2, 3J,K and 8M-P).

We also see that Ubx expression can regulate segment-specific morphology without affecting cell survival. For example, the median lineage $0 \mathrm{~A}$ neurons normally project to the $\mathrm{pI}$ commissure and elaborate their processes in $\mathrm{T} 1$ (Figure 6A), but they project past that point to the aI commissure in segments $\mathrm{T} 2$ to $\mathrm{A} 1$ (Figure 6B-D). These differences persist when cell death is blocked (Figure 6E-H). Therefore, the loss or gain of $U b x$ function is able to alter axon guidance and target recognition, presumably due to segment-inappropriate expression of signal transduction pathway components.

Besides lineage- and hemilineage-restricted patterns, we saw examples such as lineages 8,15 and 23 in which $U b x$ expression was confined to only two to three cells in the cluster. Because our analysis was at the cluster level, we could not determine whether the loss of $U b x$ resulted in the death of this small number of cells. Also, the low-level $U b x$ expression in these cells might direct later events that occur as the neurons mature during metamorphosis.

We conclude that the effects of Ubx expression are not universal for secondary lineages but instead are lineage- and even hemilineage-dependent, implying independent co-option of $U b x$ by distinct mechanisms of regulation. This ability to act as a micromanager rather than a global switch would also allow $U b x$ to sculpt numerous species-specific differences in nervous system development during insect evolution without disruption of the largely conserved neuroblast array [23,24].

\section{Candidate mechanisms for context-dependent Ubx function}

In the postembryonic CNS, $U b x$ carries out such diverse downstream functions as promoting NB or neuron death, promoting cell survival, and influencing axon guidance. These context-specific responses could be mediated through a number of different mechanisms: for example, expression levels governing threshold-dependent processes, alternative splicing, and the presence of specific cofactors and/or collaborators, any of which could influence DNA binding specificity and/or activation versus repression of gene targets.

Levels of $U b x$ expression are known to be important to developmental patterning. For example, in the Drosophila leg, gene dosage contributes to species-specific bristle patterns [25]. Moreover, low levels of Ubx are sufficient to repress an eighth bristle row on the posterior femur in T2 and T3, but higher levels are required for the repression of trichomes [26], suggesting that different levels of Ubx are required for distinct functions during development.

Similar differential responses to different levels of Ubx also appear to be in play for the postembryonic lineages since we see several cases in which neurons express Ubx at low levels in one segment but die in response to higher levels in the next. The best example is the $12 \mathrm{~A}$ hemilineage, which makes the 12id and 12im axon bundles in T1 and the 12id (but not always 12im) bundle in $\mathrm{T} 2$, and dies in T3. These differences are associated with three levels of Ubx expression in this hemilineage: none in $\mathrm{T} 1$, intermediate levels in $\mathrm{T} 2$, and high levels in $\mathrm{T} 3$. Importantly, when the 12A neurons in $\mathrm{T} 3$ are rescued by dronc mutants, they produce only the 12id bundle, but when rescued by removal of $U b x$, both the $12 \mathrm{id}$ and the $12 \mathrm{im}$ branches are produced. This suggests that low levels of Ubx prevent formation of the 12im branch, but high levels cause cell death.

The six Ubx isoforms are believed to have distinct roles in regulating target gene expression in different tissues during development $[27,28]$, but it has long been standard practice to use a single isoform for overexpression studies. While our loss of function experiments were carried out using a null allele of $U b x$, eliminating all possible isoforms, the gain of function experiments used a transgene constructed from the Ia isoform [29]. We nonetheless observed overexpression phenotypes that appeared to be the opposite of those from loss of function experiments, suggesting that Ia can substitute 
for the isoforms normally expressed in the CNS. This is consistent with reports that expressing any isoform ectopically at high enough levels can compensate for the lack of the normal one [30]. Nonetheless, it remains an untested possibility that different isoforms of Ubx are responsible for distinct functions in the postembryonic lineages.

A final possibility is that different Hox cofactors and/ or collaborators are present in the cells of different NB lineages. Cofactors of the Pbx/Meis family (Extradenticle and Homothorax in Drosophila) are TALE homeodomain proteins that bind DNA cooperatively with Hox genes to increase target specificity in vivo, reviewed in [31]. The homeodomain protein Engrailed, which is differentially expressed between the siblings of at least some lineages (JWT, unpublished work), has also been shown to be a Hox cofactor and appears to be involved specifically in target gene repression via recruitment of the co-repressor Groucho [32,33]. In addition, other transcription factors such as Teashirt and Sloppy paired appear to function as Hox collaborators at Hox-targeted cis regulatory elements [32,34,35].

\section{Conclusions}

We have found the Hox gene $U b x$ to be a key regulator of anteroposterior patterning in the postembryonic ventral nervous system of Drosophila melanogaster. In the larva, $U b x$ is not expressed homogenously within its general domain (parasegments 5 and 6), but rather in specific NB lineages and even hemilineages. $U b x$ is both necessary and sufficient for many of the segmentspecific differences in NB lineage morphology observed in previous studies. Moreover, $U b x$ acts in a contextdependent manner, promoting programmed cell death, promoting cell survival, and/or regulating axon morphology, depending on the hemilineage. In some hemilineages, the function of Ubx is segment-specific and appears to depend on the level of expression. Thus, Ubx has been co-opted during evolution for multiple roles in sculpting the postembryonic ventral nervous system in a segment-appropriate manner.

\section{Methods}

\section{Fly stocks}

This study employed the MARCM (mosaic analysis with a repressible cell marker) system, in which the FLP/FRT method is used to generate clones of cells lacking GAL80, a suppressor of GAL4 [21]. This allows a reporter gene, $U A S-m C D 8:: G F P$, to be driven exclusively in cells that are homozygous mutant for a gene of interest or in cells expressing an additional UAS-transgene of interest.

The $w, G A L 4^{C 155}$, hsFLP, UAS-mCD8::GFP; FRT82B; tubP-GAL80 and $y w ; F R T 82 B, U b x^{1}, e / T M 6 \beta$ stocks, and the parent lines we used to generate a novel $y w ; F R T 82 B$,
UAS-Ubx.Ia.C/TM6 $\beta$ stock, were generous gifts from Jay Parrish and Yuh-Nung Jan (UCSF) [36]. The $p\{r y+$, neoFRT82B\}, ry stock used for WT MARCM was obtained from the Bloomington Drosophila Stock Center (Indiana University). Cell death was inhibited using flies of genotype $h s$-flp, GAL4 ${ }^{C 155}$, UAS-mCD8::GFP/+; tubPGAL80, FRT2A/dronc ${ }^{\triangle A 8}$, FRT2A [37].

\section{Generation of MARCM clones}

To generateWT control and UAS-Ubx MARCM clones, eggs of the appropriate genotype were collected for $12 \mathrm{~h}$ on grape agar plates at $25^{\circ} \mathrm{C}$, incubated at $25^{\circ} \mathrm{C}$ for $12 \mathrm{~h}$, and then heat-shocked at $37.5^{\circ} \mathrm{C}$. Treatment was similar for dronc clones except that eggs were collected for $24 \mathrm{~h}$ and then heat-shocked immediately. To generate $U b x^{-}$ MARCM clones, eggs were collected for $12 \mathrm{~h}$ on grape agar plates at $25^{\circ} \mathrm{C}$ and then heat-shocked immediately. Following heat shock, embryos or larvae were transferred to instant fly media (Carolina Biological Supply, Burlington, NC, USA) and reared at $29^{\circ} \mathrm{C}$ to increase expression of the GAL4 ${ }^{\mathrm{C} 155}$ driver and visibility of MARCM clones.

\section{Production of the anti-Ultrabithorax antiserum}

To generate Ubx antibody 7701, we first expressed a fusion-antigen using the cDNA clone RE43738 received through the Drosophila Genomics Resource Center. The sequence chosen for its low complexity and low paralogy to other genomic regions was ATGAACTCGTACTTTG AACAGGCCTCCGGCTTTTATGGCCATCCGCACCAG GCCACCGGAATGGCAATGGGCAGCGGTGGCCAC CACGACCAGACGGCCAGTGCAGCGGCGGCCGCG TACAGAGGATTCCCTCTCTCGCTGGGCATGAGTCC CTATGCCAACCACCATCTGCAGCGCACCACCCAGG ACTCGCCCTACGATGCCAGCATCACGGCCGCCTGC AACAAGATATACGGCGATGGAGCCGGAGCCTACAA ACAGGACTGCCTGAACATCAAGGCGGATGCGGT GAATGGCTACAAAGACATTTGGAACACG. The corresponding protein region is MNSYFEQASGFYGHPHQA TGMAMGSGGHHDQTASAAAAAYRGFPLSLGMSPY ANHHLQRTTQDSPYDASITAACNKIYGDGAGAYKQ DCLNIKADAVNGYKDIWNT, which corresponds to position 1-106 of the Ubx protein.

The complementary DNA sequence was cloned by LIC cloning within the pMCSG19 vector [38] to express and purify the antigen as described. The antigen was injected in rabbits by Millipore using their standard polyclonal protocol. Sera were then used to test antibody specificity by fluorescent immunostaining on Drosophila embryos (Figure 10).

\section{Immunohistochemistry}

Nervous systems were dissected from wandering third instar larvae in PBS ( $\mathrm{pH} 7.2$ ), fixed in 3.7\% buffered formaldehyde at room temperature, and then washed in 


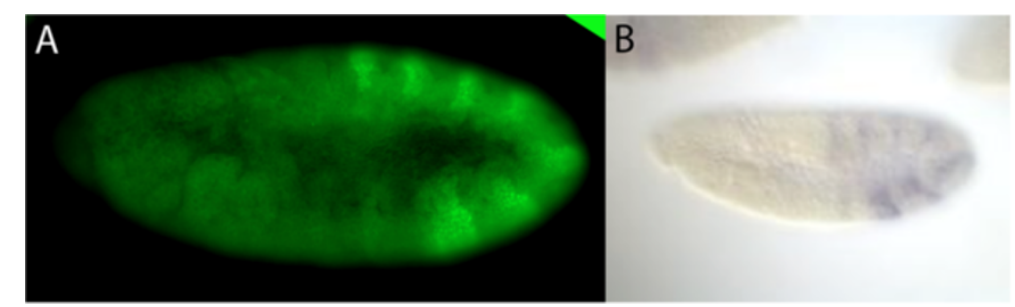

Figure 10 Staining specificity of anti-Ubx_7701 antibody. (A) Drosophila y; $c n$ bw sp embryo at stage 11 stained with the anti-Ubx_7701 antibody showing specific expression of the protein compared with (B) the cDNA expression of the clone RE43738 (Drosophila Genomics Resource Center).

0.3\% PBS-TX (PBS with $0.3 \%$ Triton-X100). Fixed samples were blocked in $2 \%$ normal donkey serum (Jackson Immunoresearch Laboratories, West Grove, PA, USA) in PBS-TX for $30 \mathrm{~min}$ and then incubated with rat antimCD8 (Caltag/Invitrogen, Grand Island, NY, USA) at $1: 100$ and either rabbit anti-Ubx at 1:1000 (7701) (Figure 10; [39]) or mouse monoclonal anti-neurotactin (BP106, Developmental Studies Hybridoma Bank, University of Iowa, Iowa City, IA, USA) at 1:30 for several days at $4^{\circ} \mathrm{C}$. After primary antibodies were washed out, tissues were incubated overnight at $4^{\circ} \mathrm{C}$ in a $1: 300$ dilution of fluorescein isothiocyanate-conjugated donkey anti-rat IgG and Texas Red-conjugated donkey antimouse IgG (Jackson Immunoresearch Laboratories). After additional washes, tissues were mounted on polylysine coated coverslips, dehydrated through an ethanol series, cleared in xylene, and mounted in DPX (SigmaAldrich, St. Louis, MO, USA).

\section{Microscopy and image processing}

Fluorescently stained nervous systems were imaged using either a $63 \times$ oil objective on a BioRad MRC 1024 confocal microscope or a $40 \times$ oil objective on a Leica SP5 Spectral Systems confocal microscope. Z-stacks were collected sequentially with averaging at 0.5 to $1.0 \mu \mathrm{m}$ intervals.

Raw data stacks were imported into ImageJ (http:// rsbweb.nih.gov/ij/) using a Bio-Formats plug-in (LOCI, University of Wisconsin, Madison, WI, USA) and either merged or projected into three-dimensional representations for analysis. Lineages were identified based on morphology, NB location, and/or projections into the neurotactin scaffold with reference to our published atlas $[9,10]$.

Images are shown as single views of three-dimensionally reconstructed and rotated confocal stacks or as single optical slices, as indicated. Confocal stacks were processed and assembled into figures using ImageJ, Microsoft Powerpoint, and the Adobe Photoshop Suite. Multiple clones are typically labeled in the same sample and often obscure one another in a simple projection. For clarity, individual clones were cropped out in their entirety and adjusted for brightness and contrast. Only the slices featuring the most relevant portion of the neurotactin axon scaffold were projected and shown as landmarks.

For selected lineages, we made two-dimensional z-projections in ImageJ to measure the diameter of the axon bundle that exited the cell cluster. We used the "straight" line-drawing tool in combination with the plot profile macro to measure the diameter of the bundle as it crossed the midline.

\section{Abbreviations}

A1: first abdominal segment; abd-A: abdominal-A; al: anterior intermediate; aV: anterior ventral; CNS: central nervous system; GFP: green fluorescent protein; GMC: ganglion mother cell; Ig: immunoglobulin; MARCM: mosaic analysis with a repressible cell marker; NB: neuroblast; PBS: phosphatebuffered saline; PBS-TX: phosphate-buffered saline with Triton X-100; pD: posterior dorsal; pl: posterior intermediate; T1: first thoracic segment; T2: second thoracic segment; T3: third thoracic segment; Ubx: Ultrabithorax; WT: wild-type.

\section{Competing interests}

The authors declare that they have no competing interests.

\section{Authors' contributions}

ECM conceived of the study, participated in the design and coordination, carried out the Ubx loss of function experiments, assisted with clonal analysis for all MARCM experiments, created figures, and drafted the manuscript. KED carried out and analyzed the Ubx gain of function experiments, assisted by ARC. DRA, KTR, and MEC carried out the wild-type and dronc Ubx expression experiments and assisted with data collection and analysis. NN and KPW generated and characterized the 7701 antibody to Ubx, created the relevant figure, and critiqued the manuscript. JWT participated in the design and coordination, carried out the early larval expression experiment, created figures, and helped to draft the manuscript. All authors read and approved the final manuscript.

\section{Acknowledgements}

We thank Susanne Rafelski for the ImageJ macros used to prepare the figures and Darren Williams for the dronc MARCM flies and early discussions. This work was supported by a Damon Runyon Fellowship Award to ECM, the Russo Fund for Undergraduate Research to KTR, the Kalman Fund for Biomedical Research Fellows to DRA and ARC, and National Institutes of Health grant NS13079 and funding from the Howard Hughes Medical Institute to JWT.

\section{Author details}

${ }^{1}$ Biology Department, Bucknell University, Lewisburg, PA, USA. ${ }^{2}$ Neuroscience Program, Bucknell University, Lewisburg, PA, USA. ${ }^{3}$ Cell Biology/Biochemistry Program, Bucknell University, Lewisburg, PA, USA. ${ }^{4}$ nstitute for Genomics \& Systems Biology, University of Chicago, Chicago, IL, USA. ${ }^{5}$ Janelia Farm Research Campus, Howard Hughes Medical Institute, Ashburn, VA, USA. 
Received: 25 May 2012 Accepted: 29 August 2012

Published: 11 September 2012

\section{References}

1. Wheeler WM: Neuroblasts in the arthropod embryo. J Morph 1891, 4:337-343.

2. Bate CM: Embryogenesis of an insect nervous system. I. A map of the thoracic and abdominal neuroblasts in Locusta migratoria. J Embryol Exp Morphol 1976, 35:107-123.

3. Hartenstein V, Campos-Ortega JA: Early neurogenesis in wildtype Drosophila melanogaster. Wilhelm Roux Arch Dev Biol 1984, 193:308-325.

4. Bauer V: Zur inneren metamorphose des zentralnervensystems der insekten. [Inner metamorphosis of insect central nervous systems] Zoologische Jahrbuecher Abteilung fuer Anatomie und Ontogenie der Tiere 1904, 20:123-150.

5. Bate CM, Grunewald EB: Embryogenesis of an insect nervous system II: a second class of neuron precursor cells and the origin of the Intersegmental connectives. J Embryol Exp Morphol 1981, 61:317-330

6. Goodman CS, Raper J, Ho RK, Chang S: Pathfinding by neuronal growth cones in grasshopper embryos. In Developmental Order: Its Origin and Regulation. Edited by Subtelny S, Green PB. New York: Liss; 1982:275-316.

7. Spana EP, Doe CQ: Numb antagonizes Notch signaling to specify sibling neuron cell fates. Neuron 1996, 17:21-26.

8. Skeath JB, Doe CQ: Sanpodo and Notch act in opposition to Numb to distinguish sibling neuron fates in the Drosophila CNS. Development 1998, 125:1857-1865.

9. Truman JW, Schuppe H, Shepherd D, Williams DW: Developmental architecture of adult-specific lineages in the ventral CNS of Drosophila. Development 2004, 131:5167-5184.

10. Truman JW, Moats W, Altman J, Marin EC, Williams DW: Role of Notch signaling in establishing the hemilineages of secondary neurons in Drosophila melanogaster. Development 2010, 137:53-61.

11. Doe CQ: Molecular markers for identified neuroblasts and ganglion mother cells in the Drosophila central nervous system. Development 1992 116:855-863.

12. Bossing T, Udolph G, Doe CQ, Technau GM: The embryonic central nervous system lineages of Drosophila melanogaster. I. Neuroblast lineages derived from the ventral half of the neuroectoderm. Dev Biol 2006, 179:41-64.

13. Schmidt H, Rickert C, Bossing T, Vef O, Urban J, Technau GM: The embryonic central nervous system lineages of Drosophila melanogaster. II. Neuroblast lineages derived from the dorsal part of the neuroectoderm. Dev Biol 1997, 189:186-204.

14. Schmid A, Chiba A, Doe CQ: Clonal analysis of Drosophila embryonic neuroblasts: neural cell types, axon projections and muscle targets. Development 1999, 126:4653-4689.

15. Truman JW, Bate M: Spatial and temporal patterns of neurogenesis in the central nervous system of Drosophila melanogaster. Dev Biol 1988, 125:145-157.

16. Rogulja-Ortmann A, Technau GM: Multiple roles for Hox genes in segment-specific shaping of CNS lineages. Fly (Austin) 2008, 2:316-319.

17. Prokop A, Bray S, Harrison E, Technau GM: Homeotic regulation of segment-specific differences in neuroblast numbers and proliferation in the Drosophila central nervous system. Mech Dev 1998, 74:99-110

18. Bello BC, Hirth F, Gould AP: A pulse of the Drosophila hox protein Abdominal-A schedules the end of neural proliferation via neuroblast apoptosis. Neuron 2003, 37:209-219.

19. Ghysen A, Jan LY, Jan YN: Segmental determination in Drosophila central nervous system. Cell 1985, 40:943-948.

20. Truman JW, Taylor BJ, Awad TA: Formation of the adult nervous system. In The Development of Drosophila Melanogaster. Edited by Bate M, Martinez Arias A. Cold Spring Harbor: C Spring Harbor Laboratory Press; 1993: 1245-1275.

21. Lee $T$, Luo L: Mosaic analysis with a repressible cell marker for studies of gene function in neuronal morphogenesis. Neuron 1999, 22:451-461.

22. White RA, Wilcox M: Distribution of Ultrabithorax proteins in Drosophila. EMBO J 1985, 4:2035-2043.

23. Broadus J, Doe CQ: Evolution of neuroblast identity: seven-up and prospero expression reveal homologous and divergent neuroblast fates in Drosophila and Schistocerca. Development 1995, 121:3989-3996.
24. Truman JW, Ball EE: Patterns of embryonic neurogenesis in a primitive wingless insect, the silverfish, Ctenolepisma longicaudata: comparison with those seen in flying insects. Dev Genes Evol 1998, 208:357-368.

25. Stern DL: A role of Ultrabithorax in morphological differences between Drosophila species. Nature 1998, 396:463-466.

26. Davis GK, Srinivasan DG, Wittkopp PJ, Stern DL: The function and regulation of Ultrabithorax in the legs of Drosophila melanogaster. Dev Biol 2007, 308:621-631.

27. Subramaniam V, Bomze HM, Lopez AJ: Functional differences between Ultrabithorax protein isoforms in Drosophila melanogaster: evidence from elimination, substitution and ectopic expression of specific isoforms. Genetics 1994, 136:979-991.

28. Gebelein B, Culi J, Ryoo HD, Zhang W, Mann RS: Specificity of distalless repression and limb primordia development by abdominal Hox proteins. Dev Cell 2002, 3:487-498.

29. Castelli-Gair J, Greig S, Micklem G, Akam M: Dissecting the temporal requirements for homeotic gene function. Development 1994, 120:1983-1995.

30. de Navas LF, Reed H, Akam M, Barrio R, Alonso CR, Sanchez-Herrero E: Integration of RNA processing and expression level control modulates the function of the Drosophila Hox gene Ultrabithorax during adult development. Development 2011, 138:107-116.

31. Mann RS, Chan SK: Extra specificity from extradenticle: the partnership between HOX and PBX/EXD homeodomain proteins. Trends Genet 1996, 12:258-262

32. Gebelein B, McKay DJ, Mann RS: Direct integration of Hox and segmentation gene inputs during Drosophila development. Nature 2004, 431:653-659.

33. Gebelein B, Mann RS: Compartmental modulation of abdominal Hox expression by Engrailed and Sloppy-Paired patterns the fly ectoderm. Dev Biol 2007, 308:593-605.

34. Robertson LK, Bowling DB, Mahaffey JP, Imiolczyk B, Mahaffey JW: An interactive network of zinc-finger proteins contributes to regionalization of the Drosophila embryo and establishes the domains of HOM-C protein function. Development 2004, 131:2781-2789.

35. Taghli-Lamallem O, Gallet A, Leroy F, Malapert P, Vola C, Kerridge S, Fasano $L$ : Direct interaction between Teashirt and Sex Combs Reduced proteins, via Tsh's acidic domain, is essential for specifying the identity of the prothorax in Drosophila. Dev Biol 2007, 307:142-151.

36. Parrish JZ, Emoto K, Jan LY, Jan YN: Polycomb genes interact with the tumor suppressor genes hippo and warts in the maintenance of Drosophila sensory neuron dendrites. Genes Dev 2007, 21:956-972.

37. Williams DW, Kondo S, Krzyzanowska A, Hiromi Y, Truman JW: Local caspase activity directs engulfment of dendrites during pruning. Nat Neurosci 2006, 9:1234-1236.

38. Donnelly Ml, Zhou M, Millard CS, Clancy S, Stols L, Eschenfeldt WH, Collart $F R$, Joachimiak A: An expression vector tailored for large-scale, high-throughput purification of recombinant proteins. Protein Expr Purif 2006, 47:446-454

39. Negre N, Brown CD, Ma L, Bristow CA, Miller SW, Wagner U, Kheradpour P, Eaton ML, Loriaux P, Sealfon R, Li Z, Ishii H, Spokony RF, Chen J, Hwang L, Cheng C, Auburn RP, Davis MB, Domanus M, Shah PK, Morrison CA, Zieba J, Suchy S, Senderowicz L, Victorsen A, Bild NA, Grundstad A, Hanley D, MacAlpine DM, Mannervik M, et al: A cis-regulatory map of the Drosophila genome. Nature 2011, 471:527-531.

doi:10.1186/1749-8104-7-31

Cite this article as: Marin et al:: Ultrabithorax confers spatial identity in a context-specific manner in the Drosophila postembryonic ventral nervous system. Neural Development 2012 7:31. 